other migratory locusts, as well as to the non-migratory species. Detailed descriptions of the various machines which were given in the original reports are, for the most part, omitted, in the belief that the figures themselves will be sufficiently suggestive for the purpose. In point of fact, many of these machines, especially the more complicated, while serviceable, cannot be recommended to the average farmer dealing with the locust plague, and experience has shown that those simple forms providing for the use of coaloil and coal-tar are, on the whole, the most efficacious against the unfledged insects. It is, therefore, to this portion of the bulletin that Professor Riley particularly calls the attention of those needing the information contained in it. But little experience of practical value has been had since the last great invasion; hence little has been added to this section of the bulletin beyond a brief description of the trapping system used in Cyprus against the migratory locusts of the Old World, and an account of the branarsenic mash remedy used in California in 1885 against the devastating locust.

\section{THE TREES OF TASMANIA.}

THE government of Tasmania has recently issued a publication, the "Tasmanian Official Record," which contains much useful and interesting information concerning the trees of that island. It is peculiarly a forest country, and many of the trees are of great dimensions, towering over and eclipsing the lesser undergrowths on plains, valleys, hills, and mountain slopes. Of the $16,778,000$ acres comprising the total area, there are only 75,000 acres occupied by lakes, and 488,354 acres of cultivated land only partially cleared of its timber. With the exception of minor areas on the tops of mountains or among the barren uplands of the western highlands, the whole of the rest of the country is occupied with an almost continuous virgin forest, mainly composed of the various forms of eucalypti (gum trees), one noted example of which, the Iolosa blue gum, has been recorded as measuring 330 feet high. Many of these trees have stems measuring 150 feet high without a branch, with a girth of about 40 feet towards the base; and it is also recorded that a blue gum at Southport (Eucalyptus globulus), the prevailing tree towards the south of the island, "contained as much timber as would fully suffice to build a 90 ton schooner."

With such a wealth of forest trees, Tasmania's sources of timber supply must be infinitely great, and in the near future must be of great industrial value; but the difficulties of transit, the ignorance of their economic value in distant markets, the plethora of local supply, and the necessity for clearing the land in the most convenient way, all tend, it is said, to produce waste and improvidence in respect of timber products, which might soon become a great source of national wealth.

The necessity for the better conservation of the natural forests in Tasmania has lately commanded the attention of the local government, and a department has been created for the purpose of establishing conserved areas, and for regulating all matters connected with the cutting of timber on government lands.

The following is a description of the more important timbers as regards their industrial value. The blue gum has its home principally in the southern parts of Tasmania, where it attains great dimensions. Many of these trees exceed a height of 280 feet, with a girth of from 40 to 50 feet. A tree called "Lady Franklin's tree," near Hobart, is stated to have a circumference of 107 feet at a height of four feet from the ground. The timber of the blue gum is of rather a pale color, hard, heavy, strong, and durable. In transverse strain its strength is about equal to English oak. It is used in house and ship building, and also by carriage builders and manufacturers of tools.

The " peppermint tree" has a wide range, as it is found in the southern and eastern humid districts of Victoria and New South Wales, as well as in Tasmania. It varies greatly with altitude, climate, and soil, and is found at all heights up to 4,000 feet elevation. In the poorer lands the trees, though tall, are not remarkably so, but in the deep wooded gullies and in the moist ravines of mountains it attains such remarkable dimensions that it has obtained the distinction of the "giant eucalyptus" of Aus- tralia. The timber of this tree is useful for many kinds of carpenters' work, as in drying it does not split. It is also used in ship-building, for keelsons and planking. Besides its timber, this tree is famous for other products of value. The ashes of the foliage yield, it is stated, ten per cent pearlash; and from one thousand pounds of fresh leaves, with their small stalks and branches, the yield of eucalyptus oil by far surpasses all that of other congeners, amounting to five hundred ounces per thousand pounds.

The stringy-bark gum is a valuable tree, found in abundance in Victoria, South Australia, and Tasmania. It is straight stemmed and of rapid growth, attaining a maximum height of 300 feet. The wood of this tree supplies a large portion of the ordinary sawn hard timber for rough building purposes. It is also well adapted for carriage, cart, and wagon building, wheelwork, and agricultural machinery, as well as for the framing of railway carriages and trucks. The white gum, or "manna tree," is abundantly distributed throughout the island, and has also a wide distribution on the mainland of Australia. Its timber is used for shingles, rails, and for rough building materials. The small branching trees on open ridges and plains are noted for exuding a sugary substance called " manna," which is esteemed a great luxury, and is eagerly sought for by the young.

The gum-topped stringy bark is held in high esteem in Tasmania, and the chief peculiarity of this tree is that, while the lower part of the butt is clothed with a thick fibrous bark, the upper part and the smaller limbs and branches are quite smooth. The timber from this tree is highly prized, and it is described by competent authorities as second only to the blue gum. The iron bark is a valuable tree attaining a height of 150 feet. The trunk is sawn into good timber, and it is also used for posts and rails.

One of the most handsome of the native trees is the blackwood, which is widely distributed along the slopes of the north-west coast. It attains a height of from 60 to 130 feet. The timber is of a brownish color, closely striped with streaks of various shades of a reddish brown. The more ornamental $\operatorname{logs}$ of this wood are exceedingly beautiful, and fetch a high price. The myrtle or beech is common in Tasmania, and forms a large proportion of the forests. The "huon" pine is said to be the grandest and most useful of all the soft woods. It is abundant along the rivers of the south-western parts of the island, attaining a height of from 60 to 120 feet, with a diameter of three to eight feet. Its timber is almost indestructible in any situation. It is largely employed, locally, for all kinds of furniture and ornamental work, and is the most highlyesteemed of all kinds of wood for the lighter sea craft. Among the other trees of Tasmania may be mentioned the red pine, oyster bay pine, silver wattle, black wattle, and native cherry.

\section{LETTERS TO THE EDITOR.}

\section{Growth of the Face.}

DURING the past year investigations upon the physical growth of children have been conducted in the Worcester schools. The preliminary tables on the growth of the female face bring out some facts of considerable interest. There seem to be three distinct periods, the first ending about the seventh year, and the third beginning about the fifteenth year. A striking peculiarity is the seemingly abrupt transition from the types of one period to those of the succeeding. The sudden disappearance of the lower widths of face, and the equally sudden appearance of the types of the succeeding period, e.g., the sudden shooting up of the widths to almost adult dimensions at about the age of eight or nine offset by the equally sudden disappearance of the distinctively childish characteristics at the age of eleven. These peculiarities also appear at the ages of twelve and fourteen respectively in the succeeding period. This would seem to indicate the very slow growth of some children until the ages of about eight and fourteen respectively are reached, and then a very rapid development of each individual to her proper position in the series. This Axel Key found also to be true with respect to the total height of the Swedish children observed by him.

In the second period very many of the forms are already adult, and, if not at their fullest development, have very nearly ap- 
proached it. From the fifth to the tenth year inclusive the growth is somewhat slow, about 6.5 millimetres in all, but for the next four years, the period of adolescence, the growth is 6.2 millimetres. From the fourteenth year on there is very little advance, the maxi-

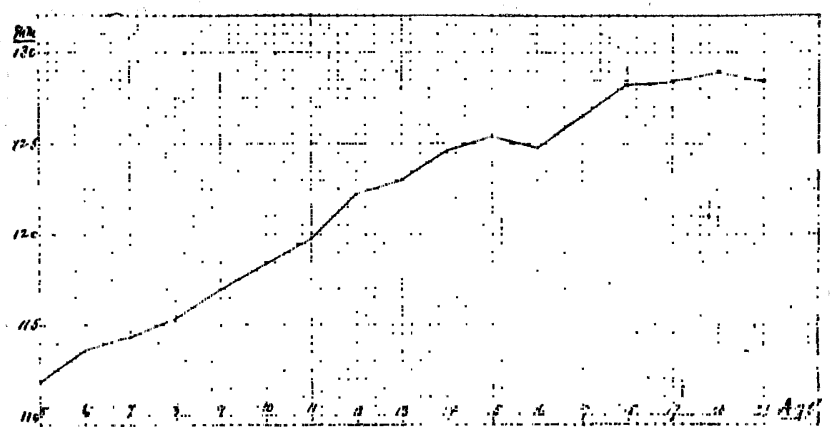

mum seeming to be reached at about 128 millimetres in the twentieth year.

On comparing this growth with that of the male face some differences are noticeable. The male face is, with perhaps a single exception, larger for the same period of life and for the same years:

\section{BOOK-REVIEWS.}

The Evolution of Marriage and of the Family. By CH. LETOURNEAU, New York, Scribner. 373 p. \$1.25.

Among the distinguished French students of sociology, Professor Letourneau has long stood in the first rank. He approaches the great study of man free from bias and shy of generalizations. To collect, scrutinize, and appraise facts is his chief business. In the volume before us be shows these qualities in an admirable degree. The subject is one of the most vital in social dynamics, for the relation of the sexes is the foundation of primitive society, and on primitive rests and grows all higher social development.

He dismisses as unfounded the extravagant views of McLennan, Lubbock, and our own countryman, Morgan, who would identify primitive marriage with sexual promiscuity. Here, as elsewhere, his opinions are based not merely on the facts of ethnography, but on numerous analogies drawn from the higher orders of the animals inferior to man: for Letourneau holds, along with all other leading ethnographers, that in the senses and emotions man reveals no other distinction above the beast than one of degree, nowhere one of kind; and to understand the motives and customs of the savage state, more is learned from the brute than from the civilized man.

\begin{tabular}{|c|c|c|c|c|c|c|c|c|c|c|c|c|c|c|c|c|c|}
\hline \multirow{2}{*}{ Millimetres. } & \multicolumn{17}{|c|}{ Age in Years. } \\
\hline & 5 & 6 & 7 & 8 & 9 & 10 & 11 & 12 & 13 & 14 & 15 & 16 & 17 & 18 & 19 & 20 & $21+$ \\
\hline $100-101$ & 1 & & & & & & & & & & & & & & & & \\
\hline $102-103$ & & & & 1 & & & & & & & & & & & & & \\
\hline $104-105$ & 1 & & 2 & 1 & & & & & & & & & & & & & \\
\hline $106-107$ & 2 & 4 & 2 & 3 & & 2 & & & & & & & & & & & \\
\hline $108-109$ & 3 & 4 & 2 & 4 & 3 & 1 & & & & & & & & & & & \\
\hline $110-111$ & 6 & 14 & 9 & 8 & 6 & 4 & 4 & & & & & & & & & & \\
\hline $112-113$ & 8 & 13 & 20 & 12 & 9 & 5 & 5 & 3 & 1 & 3 & & & & & & & \\
\hline $114-115$ & 9 & 10 & 16 & 13 & 14 & 16 & 12 & 4 & 4 & 1 & & & & & & & \\
\hline $116-117$ & & 10 & 15 & 9 & 19 & 18 & 15 & 13 & 6 & 1 & & 1 & & & & & \\
\hline $118-119$ & 1 & 5 & 13 & 18 & 14 & 25 & 22 & 14 & 10 & 6 & 1 & 1 & & & 1 & 1 & 1 \\
\hline $120-121$ & & 1 & 4 & 8 & 11 & 23 & 18 & 14 & 16 & 9 & 5 & 2 & 1 & 1 & 1 & & 2 \\
\hline $122-123$ & ' & & & 7 & 3 & 15 & 19 & 18 & 13 & 14 & 8 & 4 & 1 & & 1 & 3 & 2 \\
\hline $124-125$ & 1 & & & 1 & 4 & 5 & 14 & 22 & 2) & 18 & 9 & 8 & 2 & 3 & 4 & 3 & 5 \\
\hline $126-127$ & & & & & 3 & 3 & 6 & 11 & 15 & 15 & 10 & 3 & 2 & & 4 & 7 & 5 \\
\hline $128-129$ & & & & & & 1 & .5 & 5 & 4 & 7 & 9 & 3 & 2 & 2 & 6 & 3 & 3 \\
\hline $130-131$ & & & & & 1 & & & 4 & 6 & 5 & 2 & 1 & 1 & 4 & 6 & 3 & 4 \\
\hline 132-133 & & & & & & 1 & & 1 & 3 & 3 & 1 & & 1 & 1 & 3 & 2 & 6 \\
\hline 134-135 & & & & & & 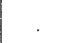 & , & 2 & 1 & 3 & 1 & 1 & & 1 & 1 & 2 & 5 \\
\hline $136-13 \%$ & & & & & & & & & & 2 & & & & & 2 & 1 & \\
\hline $138-139$ & & & & & & & & 1 & & & 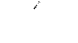 & & & & & 1 & \\
\hline $140-141$ & & & & & & & & & & & & & & & & & \\
\hline $142-143$ & & & & & & & & & & & & & & & & 1 & \\
\hline Totals. & 32 & 61 & 82 & 84 & 86 & 119 & 115 & 112 & 99 & 87 & 46 & 24 & 10 & 12 & 29 & 27 & 33 \\
\hline Averages. & 111.9 & 113.6 & 114.3 & 115.3 & 117.0 & 118.4 & 119.7 & 122.3 & 123.0 & 124.6 & 125.4 & 124.7 & 126.5 & 128.2 & 128.4 & 128.8 & 128.4 \\
\hline
\end{tabular}

it appears to grow more rapidly and continues to grow later in life. Massing the cases after twenty, the advance is seen to be far beyond the breadth attained at nineteen, rising to about 138 millimetres. At about nine years the two types approach very near, and it is not at all unlikely that, as found in the case of height by Bowditch in Boston and Peckham in Milwaukee, the female face may for a short period become the broader. Further investigations will be required to determine this point, the present investigation having been made on not more than twenty-five hundred persons, including both sexes.

Gerald M. West.
His range of comparison covers all races and extends over all conditions of society. At the close of his attractive pages he ventures to forecast the future of the institution of marriage. $\mathrm{He}$ believes that it will be a merely civil contract, monogamous in character, easily contracted, and freely dissolved by simple mutual consent of the contracting parties. Something very near this is already the case in the more enlightened of the Swiss cantons and of the United States. The utmost facility of divorce, with proper guarantees for the interest of the parties concerned,- children and parents, - is the condition to which this work, as well as other unprejudiced studies of the marital relation, unfailingly point. 